University of Nebraska - Lincoln

DigitalCommons@University of Nebraska - Lincoln

Faculty Publications, Department of Psychology

Psychology, Department of

November 1998

\title{
Reconsidering the HIV/AIDS Prevention Needs of Latino Women in the United States
}

Marcela Raffaelli

University of Nebraska-Lincoln, mraffaelli1@unl.edu

Mariana Suarez-Al-Adam

Rutgers University

Follow this and additional works at: https://digitalcommons.unl.edu/psychfacpub

Part of the Psychiatry and Psychology Commons

Raffaelli, Marcela and Suarez-Al-Adam, Mariana, "Reconsidering the HIV/AIDS Prevention Needs of Latino Women in the United States" (1998). Faculty Publications, Department of Psychology. 84.

https://digitalcommons.unl.edu/psychfacpub/84

This Article is brought to you for free and open access by the Psychology, Department of at DigitalCommons@University of Nebraska - Lincoln. It has been accepted for inclusion in Faculty Publications, Department of Psychology by an authorized administrator of DigitalCommons@University of Nebraska - Lincoln. 
Published in:

Nancy L. Roth and Linda K. Fuller, Editors, Women and AIDS: Negotiating Safer Practices, Care, and Representation (pp. 7-41). The Haworth Press, New York \& London, 1998.

Copyright (C) 1998 by the Haworth Press. Used by permission. 


\title{
Chapter 1
}

\section{Reconsidering the HIV/AIDS Prevention Needs of Latino Women in the United States}

\author{
Marcela Raffaelli \\ Mariana Suarez-Al-Adam
}

\section{INTRODUCTION}

The change in contraceptive technology in the 1960s helped to shift the focus of responsibility for contraceptive decision making to women. The same focus on females is being pursued with AIDS prevention, although women cannot control condom use. (Worth, 1989, p. 306)

Wherever women are culturally and economically subordinate to men, they cannot control or even readily negotiate safer sex, including condom use and lifelong mutual fidelity. (Merson, 1993, p. 1267)

[P]erhaps the most critical feature of many behavior changes that might prevent the sexual transmission of HIV is that they require the cooperation of another person, namely, the woman's sex partner. (O'Leary and Jemmott, 1995, p. 3)

He told me that I was being disrespectful of him. He said, "After twenty-six years ... I'm not garbage and I'm not with

Correspondence should be addressed to Marcela Raffaelli, Department of Psychology, University of Nebraska, Lincoln, NE 68588-0308. 
other women. Maybe it's you who's infected. I'm not at risk." He left the house and when he came home he was drunk. (Puerto Rican woman describing her partner's reaction to her bringing up condom use; Suarez, 1995, p. 58)

The HIV/AIDS epidemic represents an ever-increasing threat to Latino ${ }^{1}$ populations in the United States, with women being most affected by this deadly disease. In this chapter, we explore the challenges Latino women face as they attempt to reduce their risk of sexual transmission of HIV, the virus that causes AIDS. Our main interest lies in examining how the economic, cultural, and social realities of women's lives contribute to their risk of HIV infection and constrain their ability to reduce that risk. Because there is neither a cure for AIDS nor a vaccination to block HIV transmission, prevention of infection is the main objective of the global AIDS strategy (WHO, 1992). Discussions of HIV prevention among women typically emphasize the need to develop an unobtrusive female-controlled method that kills HIV and other pathogens while permitting conception (e.g., Stein, 1990; Worth, 1989). However, development of such a method has remained elusive, and current prevention efforts focus largely on promoting consistent condom use, which has been identified as the most effective HIV prevention strategy other than abstinence or a lifelong mutually monogamous relationship with an uninfected partner (Kaemingk and Bootzin, 1990; WHO, 1992). Secondary strategies such as reducing the number of partners appear to be less effective (Reiss and Leik, 1989), particularly when the risk status of partners is difficult to ascertain.

The quotations at the start of this chapter highlight the challenges women face as they attempt to reduce their risk of HIV infection by negotiating safer sex with their partners. In common with women all over the world, Latino women may be unable to assert themselves in their sexual relationships and may have great difficulty making the behavior changes needed to reduce the risk of HIV transmission. The magnitude of the challenges faced by Latino women is evident in the fact that, unlike most other population groups, Latino women have not increased their use of condoms (e.g., Remez, 1993; Stewart, 1993). One large-scale longitudinal survey of non-Hispanic white, black, and Hispanic heterosexuals living in San Francisco revealed that Hispanic women were the only ethnic/gender group to show no increase in condom use over time (Catania et al., 1993). Assessments at two time points one year apart revealed that the proportion of Hispanic women reporting occasional condom use did not change ( 20 percent versus 21 percent), whereas the proportion of black women who sometimes used condoms increased from 21 percent to 26 percent. In fact, consistent condom use among Hispanic women actually decreased from 8 percent at Wave I to 3 percent at Wave II, compared to an increase from 5 percent to 14 percent among black women.

The lack of behavioral change among the general population of Latino women is reflected in epidemiological surveillance data. In 1993, the AIDS case rate for Hispanic women was 6.4 times higher than the rate for non-Hispanic white women, and the rate for Hispanic men was 2.6 times higher than for non-Hispanic white men (CDC, 1994). Although Hispanic women represent just under 10 percent of the U.S. female population (U.S. Bureau of the Census, 1995), they account for 20 percent of cumulative female AIDS cases (CDC, 1995); Hispanic men represent 10.6 percent of the U.S. male population and 16.8 percent of cumulative male AIDS cases. To date, heterosexual transmission accounts for a larger proportion of diagnosed AIDS cases among Hispanic women ( 44 percent) than either white (37 percent) or black (33 percent) women (CDC, 1995), and the proportion of AIDS cases attributable to heterosexual transmission has increased from 27 percent in 1984 to 34 percent in 1987 (Holmes, Karon, and Kreiss, 1990) and 47 percent in the period of 1994 through 1995 (CDC, 1995). Among certain Latino subgroups, sexual intercourse has long been the main transmission route, as can be seen when female AIDS cases reported since the start of the epidemic are examined by birthplace. Although injection drug use (IDU) is the predominant exposure category among Latino women born in the United States (56 percent) and Puerto Rico (46 percent), it accounts for under a quarter of cases among women born in other Latin American countries where heterosexual intercourse is the main exposure category (Diaz et al., 1993). 
Latinos constitute the fastest growing ethnic group in the United States (Marin, 1993), and the proportion of Latino women affected by heterosexual transmission of HIV can be expected to increase. These statistics reinforce the need for information in which to ground preventive interventions for Latino populations, especially women. This chapter focuses on factors that put Latino women at continued risk of HIV infection and attempts to identify alternatives to risk reduction strategies which focus on the individual. It is divided into four main sections. In the first section, we identify factors that contribute to Latino women's risk of HIV infection and assess how realistic it is to advocate that women "negotiate" safer sex with their partners. In the middle sections, we summarize the results of HIV prevention efforts and discuss the limited applicability of traditional approaches to HIV prevention to disenfranchised women. In the final section, we discuss directions for future intervention efforts and attempt to identify approaches that hold promise in reducing Latino women's risk of HIV infection. Because women who are at risk from injection drug use face different issues than women whose main source of risk is heterosexual intercourse, we focus primarily on issues related to the sexual transmission of HIV.

\section{FACTORS THAT AFFECT LATINO WOMEN'S ABILITY TO IMPLEMENT RISK REDUCTION MEASURES}

A number of factors contribute to Latino women's risk of HIV infection and limit the extent to which they can reduce that risk (for a discussion of issues confronting women in general, see Amaro, 1995; Heise and Elias, 1995; O'Leary et al., 1993; Weiss and Gupta, 1993; Worth, 1989; Wyatt, 1994). In addition to risk factors that are common to women from all ethnic groups (such as poverty and violence), Latino women living in the United States confront additional challenges, including cultural factors that delineate appropriate sexual behavior and constrain women's power in their sexual relationships, and the pressures of immigration and acculturation. Although these factors are discussed separately below, it is important to recognize that in real life, they are intertwined and may interact in complex ways.

\section{Poverty}

Socioeconomic status can contribute both directly and indirectly to an increased risk of HIV infection among women (Mays and Cochran, 1988; O'Leary et al., 1993). Many poor women have inadequate access to health care and information about prevention of HIV and other sexually transmitted diseases, which puts them at direct risk of infection (Quinn and Cates, 1992). Poor women may also feel so overwhelmed by the stress of daily life that protecting themselves from HIV/AIDS is low on their list of priorities (Kalichman, Hunter, and Kelly, 1992; Nyamathi and Vasquez, 1989). In addition, it has been proposed that stress may lead to a direct risk of HIV infection because some women cope with stress by engaging in sexual activity (Kalichman et al., 1995) or injecting drugs (Nyamathi, Stein, and Brecht, 1995). Finally, impoverished women may lack the resources to leave a relationship with a high-risk partner, and others may depend on sex as a survival activity (Mays and Cochran, 1988). Thus, poverty limits women's options and may diminish their motivation to change high risk behavior or their ability to insist that partners comply with requests for condom use.

Latino populations are disproportionately represented among disenfranchised populations in the United States, and are thus at a higher risk of HIV infection. With the exception of CubanAmericans, Hispanics are more likely than non-Hispanic whites to be poor, attend inadequate schools, to not complete high school, to be unemployed, and suffer from increased morbidity and mortality rates (Torres, 1991). These various factors contribute to an increased risk of HIV infection among some Latino women, and may limit their ability to implement risk reduction efforts.

\section{Cultural Factors}

Another set of factors that may make it difficult for Latino women to reduce their risk of HIV infection are cultural norms that define appropriate behavior and regulate gender roles. In any discussion of cultural norms, it is important to recognize that norms define ideals rather than actual behavior, that individuals will vary in their adherence to norms, and that it is important not to overstate the role cultural factors play in explaining individual behavior 
(De La Cancela, 1989). It is also important to recognize that the meaning of a behavior differs for those raised in the culture and those observing it from outside (LeVine, 1984). Finally, the extent to which different Hispanic subgroups will subscribe to these norms will differ (Fernandez, 1995).

Recognizing these caveats, there is a good degree of consensus on characteristics of traditional Hispanic culture that may contribute to the risk of HIV infection, especially culturally defined gender roles that define and limit the behavior of men and women. As discussed below, these culturally defined gender roles can be expected to influence women's ability to negotiate safer sex in a number of ways; in particular, Latino women who attempt to introduce condom use into a relationship may experience difficulties (Forrest et al., 1993; Kenen and Armstrong, 1992; Nyamathi et al., 1995; Stewart, 1993).

One aspect of Hispanic culture that may limit the degree to which women can implement safer sex strategies involves the degree to which they and their partners subscribe to traditional gender roles of machismo and marianismo. These idealized gender roles are complementary and opposite, with men being considered strong, rational, virile, and independent while women are thought of as submissive, sentimental, chaste, and dependent (e.g., Comas-Diaz, 1987; Gilmore and Uhl, 1987; Goldwert, 1985; Magana and Magana, 1992; Marin, 1988; Panitz et al., 1983; Thompson, 1991; Wiest, 1983). The concept of machismo is an important and often misunderstood aspect of Hispanic gender role expectations, with traditional machismo incorporating responsibilities as well as rights. Male responsibilities include providing economically for the family, defending its welfare, and procreating children to carry on the family name. A man's rights include controlling the behavior of family members and having authority over them. Males are socialized to be sexually active and virile, and extramarital activity is considered a male prerogative.

The complement to machismo is marianismo. Whereas boys are taught to be active and in control of those around them, girls are taught to be self-sacrificing and dutiful, and to bow to the will of the men in their lives (first their fathers, and later their husbands). In contrast to boys, who are expected to be sexually active, girls are taught the importance of female virginity before marriage and faithfulness afterward. This sexual double standard results in dichotomization of women into "good" and "bad," with "good" women (mothers and wives) being disinterested in sex and ignorant about sexual matters and "bad" women being sexually available and knowledgeable. Women who attempt to introduce condom use into a relationship may be going against traditional gender roles in several ways, including defying the male prerogative of controlling family members' behavior and exhibiting knowledge about, and interest in, sexual behavior.

Although in recent years, a number of authors have challenged traditional depictions of Hispanic gender roles as stereotypical and invalid (e.g., Amaro, 1988b; De La Cancela, 1989; Singer et al., 1990), there is evidence that features of these idealized roles are reflected in the attitudes and behavior of at least some Latino subgroups. First, research on male and female roles within the family supports the notion that although many Latino families are more egalitarian than traditional depictions would imply, there is also evidence of male domination and control. For example, Powell (1995) reported that in a group of 29 Mexican men living in the United States, 58 percent agreed that "a wife should do whatever her husband wants" and 69 percent agreed that "husbands should make all the important decisions in a marriage."

A second body of evidence supporting the reality of culturally defined gender roles exists in the finding that as a group, Latino women are dissatisfied with their sex lives. In a study of 137 MexicanAmerican women, Amaro (1988b) found that some aspects of stereotypical gender beliefs held true; for example, the majority of women (66 percent) agreed that sex is more of a duty than a pleasure for women, and few (6 percent) said they enjoyed or felt happy in their sexual relationship. Similarly, Worth (1989) reported that impoverished Puerto Rican women who participated in a group program in New York were dissatisfied with their sex lives and complained about their partners' sexual behavior.

A third example points to research on communication styles which reveals that Mexican women's preferred strategies to deal with unwelcome requests from their intimate partners tended to reflect conventional gender role expectations (Belk et al., 1988). 
Finally, research on sexual behavior suggests that many Latino men and women adhere to culturally defined gender role expectations. For example, Latino women engage in lower levels of sexual activity than either non-Hispanic white or black women (Grimstead et al., 1993), and Latino men engage in higher levels. These separate strands of research converge to support the notion that traditional gender roles play a part in regulating the sexual behavior of Latino men and women.

Another aspect of many Latino women's lives, consistent with traditional gender role expectations, is that their partners may engage in sexual activity with other partners. Compared to other ethnic groups, Hispanic men are more likely to have multiple sexual partners (Billy et al., 1993); further, if married, Hispanic men are more likely to engage in extramarital activity (Choi, Catania, and Dolcini, 1993; Marin, Gomez, and Hearst, 1993). It has also been suggested that cultural definitions of machismo permit a man to retain his male identity even if he engages in same-sex activity, as long as he takes the "active" (insertive) role (Carrier, 1976; Carrier, 1985; Magana and Carrier, 1991; Parker and Carballo, 1990). Although same-sex activity may not be as common as ethnographic research suggests, U.S. surveys reveal that Latino men are more likely than men from other ethnic groups to report homosexual contact and Latino women are more likely to report having a main partner who has sex with men. In a nationally representative survey of men aged 20 to $39,4.8$ percent of Hispanic men, compared to 2 percent of non-Hispanic men, reported same-gender sexual contact in the past ten years; 2.8 percent of Hispanic men (versus 1 percent of non-Hispanics) reported only same-gender contact, meaning that 2 percent had engaged in sexual activity with both same and opposite sex partners (Billy et al., 1993).

A study of 620 nonpregnant women living in southern Florida revealed that Hispanic women were more likely than non-Hispanic women to report unprotected sex with a bisexual main partner (23 percent versus 13 to 14 percent of white, American-born black, and Haitian women) (Harrison et al., 1990). These U.S. findings are reinforced by research with Mexican populations. One study of Mexican men in a town on the U.S.-Mexican border revealed that 27 percent of men who engaged in same-sex activity had also engaged in vaginal intercourse during the past month (Ramirez et al., 1994). Another group of researchers also found that 27 percent of men recruited at "gay" locations (e.g., gay discos, bars, parks frequented by gay men) in six Mexican cities had engaged in sex with both male and female partners in the previous year (Izazola-Licea et al., 1991). This research suggests that Latino women have a higher probability than non-Latino women of having a nonmonogamous sex partner, making condom use in primary relationships a necessary safeguard for many women. Yet, other features of traditional Hispanic culture make the introduction of condoms problematic.

One factor limiting women's ability to negotiate safer sex with their partners is that several aspects of Latino culture make it difficult for men and women to discuss sexual topics (e.g., Forrest et al., 1993). This reflects expectations that males be knowledgeable and assume the dominant role in sexual encounters, and females be ignorant and assume the subordinate role. It also reflects a broader cultural reticence regarding sexual topics (O'Donnell, San Doval, Vornfett, and De Jong, 1994; Singer et al., 1990). This cultural taboo is evident in a study examining to whom HIV-positive men disclosed their diagnosis; 69 percent of Spanish-speaking Hispanics, compared to 88 percent of English-speaking Hispanics and 96 percent of whites, had disclosed their serostatus to their intimate partner (Mason et al., 1995). Another study revealed that fewer Latino men and women had discussed AIDS-preventive behaviors with their sex partner during the past year ( 35 percent of Latinos versus 49 percent of African Americans and 65 percent of whites) (Singer et al., 1990). In addition, sexual communication, which has emerged as a predictor of condom use in most populations (e.g., Catania et al., 1989; for a review, see Fisher and Fisher, 1992), does not appear to play a similar role among Latinos. In fact, one study revealed that higher levels of condom use among Latino men were associated with "not discussing [italics added] condom use with wives or girlfriends" and believing that "talking about condoms destroys romance" (Mikawa et al., 1992, p. 430). The nature and function of sexual communication among Latino couples is little understood, and research on this topic is urgently needed; however, it is clear that talking about sex is often unacceptable, so efforts to 
communicate directly about sexuality and HIV/AIDS prevention are likely to be problematic.

Related to this reticence regarding sexual topics is a resistance to condom use and a preference for "unobtrusive" methods of birth control in most Latino groups. Surveys of family planning methods used by married couples in Latin America (conducted during the 1980 s) reveal that the only country where more than 3 percent of married couples used condoms was Costa Rica, where 13 percent of couples reported condom use (Robey et al., 1992, Table 2). It should be noted, however, that nonuse of condoms among Latin populations does not appear to be linked to religious prohibitions as has been suggested (e.g., Ickovics and Rodin, 1992). These same surveys reveal that contraceptive prevalence was over 50 percent in most Latin countries (including Mexico), but female sterilization and oral contraceptives were the most common method. It appears that in the United States, Latinos have maintained negative attitudes toward condoms (e.g., Singer et al., 1990) as well as a preference for unobtrusive methods of birth control (e.g., Amaro, 1988b). Latinos in the United States are less likely to report condom use than members of other ethnic groups (Catania et al., 1992; Lauver et al., 1995; O'Donnell, San Doval, Vornfett, and O'Donnell, 1994). A nationally representative survey of never-married American women revealed that only 24.5 percent of Hispanic women among those surveyed had ever used condoms, compared to 48.6 percent of white women and 28.2 percent of black women (Remez, 1993). A study of 15-to-24-year-old men and women in Detroit revealed that Hispanics were less likely than African Americans to report ever using condoms with main, secondary, and casual partners (Ford, Rubenstein, and Norris, 1994). Not surprisingly, Latinos have more negative attitudes toward condoms than other ethnic groups. For example, in another study, 38 percent of Hispanic men and 27 percent of Hispanic women (compared to 19 percent of AfricanAmerican men and 14 percent of African-American women) agreed that "[c]ondoms are too much trouble to use," and Hispanic men were twice as likely as African-American men (24.5 percent versus 12.6 percent) to agree that " $[\mathrm{m}]$ ost women use some other kind of birth control, so condoms aren't necessary" (O'Donnell, San Doval,
Vornfett, and O'Donnell, 1994, p. 144). Unfamiliarity with condoms and resistance to their use is a major barrier for women to overcome.

Perhaps a greater challenge to women's attempts to implement condom use is the fact that Latino men have more negative condom attitudes than women (Marin et al., 1993; San Doval et al., 1995), and qualitative research reveals that Latino men hold negative perceptions of women who carry condoms or request condom use (Forrest et al., 1993). This is thought to reflect the fact that condoms have traditionally been associated with "illicit" sexual relationships, and are more acceptable in nonprimary relationships (e.g., Marin, Gomez, and Hearst, 1993). For example, Hispanic men recruited at a sexually transmitted disease clinic were less likely to report intending to use condoms the next time they had sex with a primary (54 percent) as compared to a nonprimary ( 90 percent) partner (San Doval et al., 1995). An additional barrier to condom use is that a woman's request that a main sexual partner use a condom may be perceived as proof of distrust, infidelity, or disrespect (Amaro, 1988b). In the clinic sample recruited by San Doval and colleagues (San Doval et al., 1995), most men (93 percent) said they would use a condom if their primary partner "insisted"; however, responses to other questions administered in this same study suggest that their partners would have substantial barriers to overcome. Over onetenth of the men (13 percent) said they would be angry if their primary partner " $[t]$ ried to talk me into using condoms," and only about one-third ( 35 percent) agreed that it "[i]s okay for $m y$ sex partner to carry condoms" (San Doval et al., 1995, p. 392). Considering that this study population was actively seeking care at a sexually transmitted disease clinic, we can predict that attitudes in the general population will be even less supportive of condom use in primary relationships.

In sum, various factors related to traditional Hispanic cultureincluding gender role expectations, the sexual double standard, norms regarding sexual communication, and preferred contraceptive practices - may contribute in different ways to Latino women's risk of HIV infection, and differ in how these factors influence women's ability to negotiate safer sex with their partners. Traditional barriers to HIV/AIDS risk reduction may diminish as individuals become more acculturated; however, adapting to a new culture 
may lead to different challenges and sources of risk. We turn next to an examination of how these factors may influence Latino women's ability to implement risk reduction measures.

\section{Immigration and Acculturation Stress}

Acculturation is the process by which migrants learn about and adapt to the host culture (e.g., Marin and Marin, 1991). Although there is a good deal of debate over how to operationalize and measure acculturation (e.g., Fernandez, 1995; Negy and Woods, 1992), most theorists agree that it is an important factor in describing the life experience of Latinos. Acculturation is significant in discussions of HIV/AIDS prevention because the acculturation process is linked to risk status in a number of ways. At the most basic level, immigrants to the United States may be unable to speak English and have difficulty communicating with social service agencies or health care providers, making it difficult to obtain health services and information. Studies consistently show that less acculturated Hispanics have lower levels of AIDS-related knowledge than more acculturated Hispanics (Epstein et al., 1994; Marin and Marin, 1990; Nyamathi et al., 1993; Rapkin and Erickson, 1990). Second, immigrants must often deal with prejudice, discrimination in housing, and limited employment options, all of which limit their economic opportunities and lead to increased life stress. Finally, the acculturation process has been identified as a significant source of stress for both individuals and families (Padilla, 1980; Vega and Miranda, 1985). Perhaps most important, immigrants are exposed to new models of behavior and situations that may challenge traditional beliefs and norms which cause friction between family members.

Traditional Hispanic culture has been described as both a protector and risk factor for Latino women. Less acculturated women tend to be at lower risk of HIV infection from their own behavior; for example, they have fewer sex partners (Marin et al., 1993; Nyamathi et al., 1993; Rapkin and Erickson, 1990; Sabogal et al., 1995). On the other hand, less acculturated women may be at risk from their partners' behavior and from traditional attitudes toward condom use. In one study of women, 72 percent of less acculturated Hispanics, compared to 54 percent of more acculturated Hispanics, and 37 percent of African-Americans, reported that their partner did not like to use condoms (Nyamathi et al., 1995). If they adhere to traditional gender role expectations, Latino women may be reluctant or unable to initiate discussions of condom use or HIV prevention. Acculturation to the mainstream Anglo culture may be linked to an increase in women's power in their personal relationships. One study that included a sample of young, highly acculturated Hispanic women who were either injection drug users or partners of IDUs revealed that women reported a high degree of power in their personal relationships and many reported being successful in persuading their partners to use condoms (Kline, Kline, and Oken, 1992). However, among non-IDU populations, highly acculturated Latino women are often at increased risk of HIV infection from their own sexual behavior. Higher levels of acculturation have consistently been linked to an increase in the number of sex partners among Hispanic women (Marin et al., 1993; Nyamathi et al., 1993; Rapkin and Erickson, 1990; Sabogal et al., 1995). At the same time, condom use has remained low even among more acculturated Latinos; Marin and colleagues (Marin et al., 1993) reported that 71 percent of English-speaking Hispanic women never used condoms, compared to 53 percent of non-Hispanic white women (79 percent of Spanish-speaking women reported never using condoms). Thus, it appears that in the process of acculturation, Latino women may be shedding some of the behavioral restraints imposed by traditional gender roles, but may not be able to give up more deep-seated rules governing sexual behavior and partner relationships.

The process of acculturation and of adjusting to a new way of life may also be a source of stress for the larger family unit, especially if migration results in economic disruption and unemployment (DeAngelis, 1995). Upon migration to the United States, many Latino men can no longer be the sole economic providers for the family (Wurzman, 1982). In traditional Hispanic society, when a man cannot provide for his family, he is no longer viewed as a real man by himself or others, and as a consequence, he will suffer loss of dignity and self-respect (Panitz et al., 1983). It has been suggested that under conditions of extreme stress, some Hispanic males may compensate for the loss of family authority by exhibiting "a rigid and maladaptive tyrannical and hypermasculine facade" (De La Cancela, 1986, p. 295; see also DeAngelis, 1995). This reaction to 
stress will probably have repercussions for women's ability to protect themselves from HIV infection, and in extreme cases, may be linked to domestic abuse.

\section{Domestic Violence}

It is important to note at the outset that rates of domestic violence are comparable in Hispanic and non-Hispanic families when factors such as urbanization, low income, and age are controlled (Straus and Smith, 1990). In addition, research on domestic abuse in various Latin American countries reveals that levels of abuse are no higher than in other countries around the world (Heise, Pitanguy, and Germain, 1994). However, as is true in most segments of society, a significant number of Latino women are in abusive relationships that limit their ability to control their own behavior. One U.S. study revealed that one out of eight Hispanic husbands physically abused their wives during the previous year (Straus and Smith, 1990). Impoverished Latino women appear to be at higher risk of domestic violence, as suggested by a study of 48 women receiving general (not abuse-related) services at two community-based organizations serving impoverished Latino populations (Suarez, Raffaelli, and O'Leary, 1995). Two-thirds of the women had experienced at least one act of physical violence from their current sex partner at some point in the relationship: 61 percent of the women had been pushed or shoved; 33 percent slapped; 29 percent kicked, bitten, or hit; and 11 percent threatened with a knife or gun. When asked why their partner had physically abused them, some women attributed the violence to their partner's desire to control them. For example, one women said her partner slapped her because "he wants to have full control of me" and another said her partner's behavior had "taught me to control myself better. I don't instigate him anymore." Other women explicitly linked the abuse to their own failure to behave in a culturally appropriate way; for example, one women said her partner abused her because she did not "treat him the way that a good Puerto Rican girl raised in Puerto Rico would treat her husband."

Because machismo condones the control of women, it has been proposed as a factor in spousal abuse (Loizos, 1978; Straus, 1983). Although this issue has not been systematically investigated, a study of barriers to condom use found that one-third of less acculturated Hispanic women said they were afraid of getting hurt if they asked their partner to use condoms (compared to 12 percent of acculturated Hispanics and 20.5 percent of African Americans (Nyamathi et al., 1995). The small-scale abuse study described above also asked women to rate their partner on a hypermasculinity scale and found significant correlations between hypermasculinity and both psychological and physical abuse (Suarez, 1995). Without investigating this issue more directly, it is impossible to draw conclusions about linkages between machismo and abuse; however, it is clear that a significant proportion of Latino women experience abuse in their intimate relationships.

Women who experience or fear abuse are at risk of HIV infection for several reasons. These women will probably be less able to assert themselves, since abused women are reluctant to risk angering their partner by suggesting that condoms be used (Amaro, 1995; Worth, 1989). In addition, abuse may take the form of rape or other coerced sexual activity which precludes HIV-prevention measures (Heise, Pitangay, and Germain, 1994). Finally, physical and psychological abuse have been linked in the general population to negative outcomes including depression and low self-esteem (Campbell, 1989; Ferraro, 1979; Mitchell and Hodson, 1983), and passivity and lack of assertion (Launius and Lindquist, 1988), all of which may interfere with a woman's motivation and ability to protect herself from HIV. Thus, women who are in abusive relationships or who fear negative partner reactions will be less able to engage in risk reduction behavior.

The social, economic, and cultural realities of Latino women's lives present serious challenges to risk reduction efforts. Many Latino women live in poverty and lack adequate access to health care and information, necessary precursors to behavior change. In addition, Latino women may experience culturally sanctioned inequality in their personal relationships and lack support for risk reduction efforts. Even if a woman knows or suspects that her partner engages in sexual activity outside the relationship, her subordinate status will likely leave her unable to insist on preventive measures. For the subset of women who experience or fear abuse, attempts to negotiate condom use or discuss HIV prevention may 
lead to physical harm. These challenges are considerable, and raise the question of whether HIV/AIDS prevention programs can be successful in helping Latino women implement and maintain behavior change in their sexual relationships. We turn now to an examination of the available research on this topic.

\section{TRADITIONAL APPROACHES TO HIV PREVENTION}

Risk reduction interventions promoting consistent condom use and other safer sex strategies have resulted in dramatic behavior change in specific U.S. populations, most notably among selfidentified gay men living in urban settings (e.g., Catania et al., 1991; Ekstrand and Coates, 1990; Kelly et al., 1989; Silvestre et al., 1993; Stall, Coates, and Hoff, 1988; Winkelstein et al., 1987). Unfortunately, the success of similar interventions in promoting behavioral change among women is less impressive.

It is only recently that HIV prevention efforts have focused on women; initial efforts targeted current or past injection drug users (IDU), who make up the majority of women diagnosed with AIDS to date. Changes in sexual behavior have been reported in studies targeting women involved with drugs, although the number of studies including Latino women has been small. One study testing the efficacy of a skills-building approach in reducing sexual risk behavior among 91 female methadone patients (64 percent Hispanic) found positive but modest gains two weeks after the intervention ended (Schilling et al, 1991). Most notably, women in the intervention group were more likely to obtain, carry, and use condoms and to report feeling comfortable talking to their partners about safe sex. In addition, 64 percent of the intervention group, compared to 36 percent of the control group, reported sexual behavior change at the two-week follow-up; a 15-month follow-up of 62 women revealed that some gains were maintained, including condom use, comfort discussing sexual issues, and positive attitudes toward HIV/AIDS prevention (El-Bassel and Schilling, 1992). Unfortunately, this study did not report results by ethnicity, so it is impossible to tell whether Latino women were as likely to report behavior change as non-Latino women.
Heterosexual women who are not injection drug users have only recently become the target of intervention efforts, and few of these interventions have been published (Moore, Harrison, and Doll, 1994). A small number of intervention programs involving primarily African-American women have demonstrated significant (but modest) sexual behavior change including redemption of condom coupons (considered a measure of behavioral intentions) (Solomon and DeJong, 1989) and changes in condom use (Hobfall et al., 1994). The most impressive outcomes were reported by Kelly and his colleagues (1994), who found that women who participated in a skills training intervention showed significant gains from baseline to a three-month follow-up. For example, women in the intervention group reported an increase in the proportion of intercourse acts during which a condom was used (from 26 percent at baseline to 56 percent at follow-up, compared to an increase from 26 percent to 32 percent among control group participants). The proportion of women reporting any condom use increased from 43 percent to 66 percent among the intervention group, but did not change among control group participants. This research suggests that well-designed interventions have the potential to bring about behavior change among at least some women; what is still unknown is whether Latino women will also benefit from comparable behavior change programs.

Few sexual risk reduction studies have included enough Latino women to examine ethnicity effects. Those studies that report on Latino women separately reveal only very minor changes, although few intensive interventions comparable to that conducted by Kelly and colleagues (1994) have been implemented. A brief (12-minute) educational intervention implemented at WIC clinics increased Latino women's levels of AIDS information and AIDS-related attitudes from pretest to an immediate posttest; however, at a retest two to three months after participation, gains in AIDS-related attitudes had disappeared and no significant differences in the behavior of experimental and control group members were observed (Flaskerud and Nyamathi, 1990). A more lengthy intervention developed by these same researchers targeted Latino women recruited at homeless shelters and drug-treatment programs (Nyamathi et al., 1994). Women received either a "specialized" intervention consisting of a 
two-hour gender and culturally sensitive program of AIDS education and skills building conducted by Latino staff or a "traditional" intervention consisting of a one-hour education program. Twoweek follow-up assessments revealed that women in the specialized group were less likely to report IDU but were no less likely to report having sex with multiple partners ( 8.5 percent compared to 6.1 percent of women in the traditional group). Unfortunately, this study did not assess condom use, so it is impossible to know whether women increased their condom use as a result of participating in the intervention.

Other interventions targeting Latino women are in the implementation or data analysis phase and their results have not yet been published (e.g., O'Donnell, San Doval, Vornfett, and O'Donnell, 1994; Weeks et al., 1995). Given the fairly modest results obtained in interventions targeting African-American and non-Hispanic white American women, it will be surprising if dramatic results are obtained. As is being increasingly recognized, even the best designed prevention programs are of limited success in promoting behavior change among women who are at greatest risk (Amaro, 1995; Heise and Elias, 1995; O'Leary and Jemmott, 1995). We turn next to an examination of the limitations of traditional HIV-prevention approaches.

\section{Limitations of Traditional Approaches to HIV Prevention}

Amaro (1995) identified three main features of models of sexual behavior on which HIV prevention programs have been based that limit their applicability to women. First, models tend to be individualistic, neglecting the broader social and cultural contexts in which sexual behavior is embedded. Second, models tend to assume that sexual activity is under an individual's control, ignoring the fact that sexual encounters are often initiated impulsively or may be coercive. Finally, models tend to ignore the extent to which sexual behavior is constrained by culturally determined factors, including gender roles, sexual values, and norms that typically result in inflexible sexual repertoires and create a power differential between men and women.

These factors all limit the usefulness of models in explaining women's sexual choices and predicting risk-taking behavior. In fact, there is mounting evidence that psychosocial variables found to predict the sexual behavior of men have limited predictive value for women (Amaro, 1995; Catania et al., 1992; for a review, see Moore, Harrison, and Doll, 1994). For example, one study examined a wide range of social and psychological predictors of HIV risk behavior among 671 primarily African-American women living in low-income housing projects in five U.S. cities (Sikkema et al., 1996). Predictor variables included HIV knowledge, age, personal risk perception, number of recent conversations with sex partners about condoms and AIDS concerns, alcohol and substance use, peer norms, risk reduction behavioral intentions, and condom barrier beliefs-variables that have been predictive in studies of male sexual behavior. In this analysis, most women ( 81 percent) at low risk were correctly classified by the study variables but only about half ( 52 percent) of women at high risk were correctly classified, suggesting that additional factors not included in current models of sexual behavior influence women's high-risk sexual behavior.

Another issue that is often ignored in prevention programs is that many women's only risk is engaging in unprotected sexual activity with one sexual partner, and the dynamics of steady relationships differ from casual or new relationships. Another analysis of the housing project data (Wagstaff et al., 1995) revealed that women who had a single partner they perceived as risky (i.e., the women were "sure" or "pretty sure" their sex partner had other partners or injected drugs) were less likely to report condom use at last intercourse than women who had multiple partners $(28$ percent versus 53 percent) and less likely to report talking to partners about condom use than women who had multiple partners ( 55 percent versus 73 percent). The two groups of women expressed similar levels of intentions to use condoms, and had equal perceptions of risk; however, these intentions and perceptions did not translate into behavior among women who were monogamous even if they knew or suspected their partners were at risk. Finally, an often ignored issue is that condom use relies not only on the cooperation of a male partner (which may be difficult to obtain) but also prevents conception, making condom use doubly problematic for many women (see Carovano, 1991; Worth, 1989). 
The limitations of traditional approaches to HIV prevention are magnified among Latino women. Of particular relevance to current risk reduction recommendations is the fact that, even if they feel vulnerable and want to change their behavior, many Latino women will be unable to "negotiate" safer sex with their partners. As described earlier, condoms are not widely used as a birth control method among Latino populations and have traditionally been associated with illicit relationships. In addition, because it is not a cultural norm for couples to discuss sexual matters, women may be reluctant to introduce the topic of condoms or attempt to negotiate safer sex with sexual partners. A woman's attempts to discuss HIV prevention in general, and condom use in particular, may be seen as inappropriate or disrespectful of the male prerogative to control the couple's sexual activity, and be taken as evidence for lack of trust. These barriers to condom use are considerable, as can be seen in the finding that 45 percent of 83 Latino women surveyed in Florida said they would not use a condom even if they knew their partner was infected with HIV, compared to 15 percent of white and 20 percent of black women (Harrison et al., 1990).

Most theorists agree that the complex interplay of economic, cultural, and social forces that define the realities of Latino women's lives present special challenges that risk reduction efforts have not been able to meet. The crux of the matter is summed up by Magana and Magana (1992): "[G]iven the subservient status of the Latino woman, it is difficult to come up with realistic strategies to help her protect herself" (p. 40). Despite this bleak reality, there are promising developments in the theoretical and applied literature on HIV/AIDS prevention that deserve further attention when considering the prevention needs of Latino women.

\section{DIRECTIONS FOR FUTURE INTERVENTION EFFORTS}

In recent years, there have been a number of conceptual and practical developments that hold promise for increasing the success of future HIV prevention efforts with Latino women. One area where advances are being made is the conceptual front, as theorists and researchers recognize the limited utility of existing models in explaining the sexual behavior of heterosexual women. By incorpo- rating explicit discussions of how gender and power dynamics influence sexual behavior, and exploring how risk behavior is influenced by these factors, the applicability of models to women's behavior will increase (Amaro, 1995). Research on what individual, partner, socioeconomic, and cultural variables predict risk and preventive behavior among subgroups of Latino women are needed. It is also imperative that the topic of sexual decision making in Latino couples be addressed directly, rather than inferring how couples negotiate sexual decisions from studies of other aspects of family decision making or distribution of power (Hurtado, 1995). In addition, qualitative research is needed to understand quantitative research findings.

The importance of conducting qualitative research was demonstrated in a study of Mexican-American men which showed that acculturation operates selectively on sexual behavior (Carrier and Magana, 1991; Magana and Carrier, 1991). In-depth field research revealed that the homosexual behavior of Mexican-American men followed either the Mexican pattern (i.e., strong role separation with emphasis on anal intercourse) or the Anglo-American pattern (i.e., less role separation with more flexible sexual repertoire). What determined the pattern men followed was the ethnicity of their early sexual partners rather than time spent in the United States or language preference (typical measures of acculturation). This finding suggests the need to get beyond simple "demographic" variables and look for ways of examining the life experience of individuals.

Another conceptual development is the growing recognition of the importance of working on the community as well as the individual level (e.g., Kelly et al., 1993). Community-level interventions incorporating mass media, outreach, and diffusion strategies as well as clinic-based programs were highly successful in bringing about changes in the gay community (Coates, 1990). Although the United States has been resistant to utilize the mass media as a channel for disseminating HIV-prevention information, promoting norms supporting prevention, and bringing about other desired group changes, there is evidence from around the world that social marketing approaches can play a significant role in HIV/AIDS prevention (Ling et al., 1992). ${ }^{2}$ Person-to-person outreach is also an effective way of promoting risk reduction; one intervention program for gay 
men successfully utilized popular community members as behavioral change agents (Kelly et al., 1992). Perhaps most important, by directing efforts at community members, prevention programs can involve current and future sex partners of intervention participants as well as the participants themselves. This is especially important for women, who may feel alienated and unduly burdened when they (rather than their sex partners) are the target of condom promotion efforts (Worth, 1989).

Prevention programs that focus exclusively on women and place the responsibility for behavior change on them ignore half of the (hetero) sexual equation (Ehrhardt, 1992; Flaskerud and Uman, 1993). Many Latino women are at risk because they lack power in their personal relationships; thus, it is imperative to target intervention efforts at men as well as women. In addition, because research suggests that Latino men control the decision to use condoms (e.g., Mikawa et al., 1992), it is counterproductive to focus condom promotion efforts exclusively on women. Given the fact that condom use is often not accepted in primary relationships, several scholars have suggested the compromise strategy of promoting consistent condom use with secondary partners (e.g., Marin, Gomez, and Hearst, 1993; San Doval et al., 1995). This would circumvent many of the barriers to introducing condoms into an ongoing relationship where conception might be desired, draw on culturally valued notions of responsibility to the family, and take advantage of the fact that condom use with secondary partners is acceptable to most Latino men.

Ultimately, however, if women are at risk as the result of their inferior social status or culturally determined expectations that are not amenable to short-term change, interventions must take this fact into account. On the pragmatic level, prevention programs for Latino women should acknowledge that condom use is a desired but not always attainable goal and give women other options that they can use. In a thought-provoking review of women-centered prevention methods, Erica Gollub (1995) attributes the continued emphasis on male condoms to "the misguided search for the perfect method" (p. 65). She points out that condoms may be the most effective way to prevent HIV transmission, but "for a woman with a partner who says no, they are 0 percent effective" (Gollub, 1995, p. 74). Because of this, Gollub urges that prevention programs give women information on the full range of available prevention methods (in a hierarchy reflecting degree of risk) so that they may choose what works best for them.

Other scholars and advocates have argued that interventions should be aimed at changing the reality of women's lives by improving their status in society. Empowerment approaches typically being women together to work toward common goals (e.g., Amaro, 1995). The potential impact of an empowerment approach is described by Heise and Elias (1995), who report on how two groups of Indian women reacted to a film on women and HIV. One group was withdrawn, embarrassed, and expressed fears of bringing up the topic of condoms with their husbands. The second group reacted differently; the women "felt capable and entitled to discuss condom use with their husbands and recommended holding a community meeting to discuss the dangers of the new disease" (Heise and Elias, 1995, p. 940). This dramatic difference was due to the fact that the second group had been participating in a community organization project for six years and was used to acting collectively to address common problems. Empowerment approaches aimed at helping women gain more control over their sexual lives have been successful among inner-city women in the United States (e.g., Levine et al., 1993). Although empowerment approaches have not been applied to HIV prevention in Latino communities, some aspects of community empowerment approaches will probably be applicable to Latino populations (for a discussion, see De La Cancela, 1989), although care must be taken to ensure that interventions are appropriate to the specific Latino community for which they are developed.

A final promising development in the prevention literature is the growth of a more sophisticated awareness of how cultural forces influence individual behavior. Although program planners have long stressed that prevention programs must be culturally sensitive, many programs for Latinos "translate" or at most, "adapt" interventions originally developed for non-Latino populations (Marin, 1993). Culture goes beyond language; however, it represents a powerful internalized force that is "experienced by the person as needs or obligations ..." (D'Andrade, 1984, p. 97). Through the process 
of socialization, individuals learn the rules of their culture and come to experience an internal pressure to obey those rules; failure to follow cultural directives is experienced as anxiety provoking (D'Andrade, 1984). Another characteristic of culture that is often ignored is that it incorporates both rational and nonrational (emotional) elements (D'Andrade, 1984; LeVine, 1984). Prevention programs cannot treat culturally derived values, beliefs, and norms as little more than opinions or facts that can be changed to conform to a more "correct" or acceptable version. Cultural meaning systems have a deeply felt and complex psychological reality that must be taken into account when developing interventions.

Gerardo Marin (1993) identified three characteristics of culturally appropriate interventions: interventions are based on values of the target group; strategies reflect the group's subjective culture; and strategies fit the preferred behavioral repertoire of the target group. Theorists have identified a number of cultural values that should be taken into account when considering the HIV/AIDS prevention needs of Latino populations (Marin, 1988; Marin, 1989). These include familismo, an emphasis on the family as the primary source of social support and identity; simpatia, an emphasis on smooth interpersonal relationships; personalismo, a preference for personal relationships and individual contact; and respeto, the need to maintain respectful hierarchical relationships. Two examples from Latin America demonstrate that by identifying themes that resonate with the target population, prevention programs can have widespread effects. In Mexico, formative research revealed that female commercial sex workers were concerned about the impact of HIV on their children rather than themselves. Mothers worried about who would care for their children if they became infected with HIV; thus, the intervention materials appealed to sex workers as mothers and urged them to stay healthy for their children's sake. Evaluations indicated significant increases in condom use, from 39 percent of women in the month before the project to 66 percent six months after its end (Liskin et al., 1989). In Colombia, after a radio campaign featured the slogan "To love with responsibility is also a man's concern," the proportion of listeners reporting that condoms were embarrassing, disrespectful to the home, vulgar, or not satisfying declined by up to 40 percentage points (Liskin et al., 1990).
These examples illustrate the effectiveness of messages incorporating culturally appropriate themes.

A second characteristic of culturally appropriate interventions is that strategies fit the target group's subjective culture. For example, many Latino men who have same-sex partners do not self-identify as "gay" or "bisexual," so they will not be reached by prevention messages aimed at these populations and may underestimate their risk of HIV infection (Magana and Magana, 1992; Marin, 1988; Marin, 1989). Special interventions will be needed to reach Latino men who have sex with both men and women, and these interventions must be couched in terms that are meaningful to the population. The third characteristic of culturally appropriate interventions identified by Marin, that interventions adhere to the preferred behavioral repertoire of the target population, is demonstrated in a project conducted by O'Donnell and colleagues (O'Donnell, San Doval, Vornfett, and DeJong, 1994). During the formative research phase of an intervention project with Hispanics, these researchers learned that participants did not want to change traditional patterns of reticence on sexual topics; rather, they wanted to learn how to protect themselves without explicit discussions. Thus, rather than focusing on changing communication patterns and trying to teach participants to talk to their partners about sex, the intervention modeled nonverbal (and minimally verbal) strategies to achieve condom use.

These simple examples all share a common theme: prevention programs reflect the values and needs of the target population. By involving members of the intended audience in the planning stages of intervention development and being open to their values and needs rather than coming in with a predetermined agenda, program planners can increase the effectiveness of their intervention. It is especially important to avoid "importing" strategies that have been successful in other population groups. For example, safer-sex eroticization (successful in promoting condom use among AngloAmerican gay men) may not be as effective in a population where sex is regarded as a woman's duty rather than a source of pleasure. Instead, it might be more acceptable to emphasize the contraceptive (Amaro, 1988b) or health (Fernandez, 1995) benefits of condom use. By using cultural norms, attitudes, and values as "enablers" 
rather than barriers, prevention planners can increase the effectiveness of their intervention programs.

Latino women in the United States, like women all around the world, are at risk of HIV infection in large part from their inferior status both in society and in their own culture. This chapter has identified some of the main factors that limit Latino women's ability to implement risk reduction measures and attempted to identify potential intervention approaches. In the short run, there is an urgent need to develop interventions that reflect the social, cultural, and economic realities of Latino women's lives and give them realistic options that they can implement without jeopardizing their relationships or their personal safety. In the long run, fundamental changes in how men and women are viewed and expected to behave will be necessary to stem the AIDS epidemic among Latino populations.

\section{NOTES}

1. The term "Latino" is used to refer to populations of Latin American origin of descent (Hayes-Bautista and Chapa, 1986); the term "Hispanic" (a census term which excludes Latinos of non-spanish origin) is used to report data utilizing this label, or more narrowly, to refer to aspects of Latino culture that can be traced back to Spanish origins. It is important to note that both these umbrella terms encompass a number of subgroups with distinct historical, political, economic, and racial differences (Amaro, 1988a); however, most scholars agree that Latino subgroups share historical and cultural features that result in significant commonalities, particularly with regard to HIV-prevention needs (e.g., Magana and Magana, 1992; Marin, 1988).

2. For a discussion of reasons for resistance to public education efforts in the United States, see Ehrhardt (1992).

\section{REFERENCES}

Amaro, H. (1988a). Considerations for prevention of HIV infection among Hispanic women. Psychology of Women Quarterly, 12, 429-443.

Amaro, H. (1988b). Women in the Mexican-American community: Religion, culture, and reproductive attitudes and experiences. Journal of Community Psychology, 16, 6-20.

Amaro, H. (1995). Love, sex, and power: Considering women's realities in HIV prevention. American Psychologist, 50(6), 437-447.
Belk, S. S., Garcia-Falconi, R., Hernandez-Sanchea, J. E., and Snell, W. E. (1988). Avoidance strategy use in the intimate relationships of women and men from Mexico and the United States. Psychology of Women Quarterly, 12, 165-174.

Billy, J. O. G., Tanfer, K., Grady, W. R., and Klepinger, D. H. (1993). The sexual behavior of men in the United States. Family Planning Perspectives, 25(2), $52-60$.

Campbell, J. (1989). A test of two explanatory models of women's responses to battering. Nursing Research, 38(1), 18-25.

Carovano, K. (1991). More than mothers and whores: Redefining the AIDS prevention needs of women. International Journal of Health Services, 2l(1), 131-142.

Carrier, J. M. (1976). Cultural factors affecting urban Mexican male homosexual behavior. Archives of Sexual Behavior, 5, 103-124.

Carrier, J. M. (1985). Mexican male bisexuality. Journal of Homosexuality, II, 75-85.

Carrier, J. M., and Magana, J. R. (1991). Use of ethnosexual data on men of Mexican origin for HIV/AIDS prevention programs. Journal of Sex Research, 28(2), 189-202.

Catania, J. A., Coates, T. J., Kegeles, S., Fullilove, M. T., Peterson, J., Marin, B., Siegel, D., and Hulley, S. (1992). Condom use in multi-ethnic neighborhoods of San Francisco: The population-based AMEN (AIDS in Multi-Ethnic Neighborhoods) Study. American Journal of Public Health, 82(2), 284-287.

Catania, J. A., Coates, T. J., Peterson, J., Dolcini, M. M., Kegeles, S., Siegel, D., Golden, E., and Fullilove, M. T. (1993). Changes in condom use among black, Hispanic, and white heterosexuals in San Francisco: The AMEN cohort survey. The Journal of Sex Research, 30(2), 121-128.

Catania, J. A., Coates, T. J., Stall, R., Bye, L., Kegeles, S. M., Capell, F., Henne, J., McKusick, L., Morin, S., Turner, H., and Pollack, L. (1991). Changes in condom use among homosexual men in San Francisco. Health Psychology, 10, 190-199.

Catania, J. A., Dolcini, M.M., Coates, T. J., Kegeles, S. M., Greenblatt, R.M., Puckett, S., Corman, M., and Miller, J. (1989). Predictors of condom use and multiple partnered sex among sexually active adolescent women: Implications for AIDS-related health interventions. The Journal of Sex Research, 26(4), 514-524.

CDC. (1994). AIDS among racial/ethnic minorities - United States, 1993. $M M W R, 43,644-647,652-655$.

CDC. (1995). HIV/AIDS surveillance report, 7(1). Atlanta: Centers for Disease Control and Prevention.

Choi, K., Catania, J. A., and Dolcini, M. M. (1993). Extramarital sex and HIV risk behavior among U.S. adults: Results from the National AIDS Behavioral Survey. American Journal of Public Health, 84(12), 2003-2007.

Coates, T. J. (1990). Strategies for modifying sexual behavior for primary and secondary prevention of HIV disease. Journal of Consulting and Clinical Psychology, 58(1), 57-69. 
Comas-Diaz, L. (1987). Feminist therapy with Hispanic/Latin women: Myth or reality? Women and Therapy, 6(4), 39-61.

D'Andrade, R. G. (1984). Cultural meaning systems. In R. A. Shweder and R. A. LeVine (Eds.), Culture theory: Essays on mind, self, and emotion, 88-119. New York: Cambridge University Press.

DeAngelis, T. (1995). Adapting to new cultures, challenges. APA Monitor, July, 48-49.

De La Cancela, V. (1986). A critical analysis of Puerto Rican machismo: Implications for clinical practice. Psychotherapy, 23(2), 291-296.

De La Cancela, V. (1989). Minority AIDS prevention: Moving beyond cultural perspectives towards sociopolitical empowerment. AIDS Education and Prevention, $1(2), 141-153$.

Diaz, T., Buehler, J. W., Castro, K. G., and Ward, J. W. (1993). AIDS trends among Hispanics in the United States. American Journal of Public Health, 83(4), 504-509.

Ehrhardt, A. A. (1992). Trends in sexual behavior and the HIV pandemic (Editorial). American Journal of Public Health, 82(11), 1459-1461.

Ekstrand, M. L. and Coates, T. J. (1990). Maintenance of safer sexual behaviors and predictors of risky sex: The San Francisco Men's Health Study. American Journal of Public Health, 80, 973-977.

El-Bassel, N. and Schilling, R. F. (1992). 15-month follow-up of women methadone patients taught skills to reduce heterosexual HIV transmission. Public Health Reports, 107(5), 500-504.

Epstein, J. A., Dusenbury, L., Botvin, G. J., and Diaz, T. (1994). Acculturation, beliefs about AIDS, and AIDS education among New York City Hispanic parents. Hispanic Journal of Behavioral Sciences, 16(3), 342-354.

Fernandez, M. I. (1995). Latins and AIDS: Challenges to HIV prevention efforts. In A. O'Leary and L. S. Jemmott (Eds.), Women at risk: Issues in the primary prevention of AIDS, 159-174. New York: Plenum Press.

Ferraro, K. J. (1979). Physical and emotional battering: Aspects of managing hurt. California Sociologist, 2, 134-149.

Fisher, J.D. and Fisher, W.A. (1992). Changing AIDS-risk behavior. Psychological Bulletin, $111(3), 455-474$.

Flaskerud, J. H. and Nyamathi, A. M. (1990). Effects of an AIDS education program on the knowledge, attitudes and practices of low income black and Latina women. Journal of Community Health, 15(6), 343-355.

Flaskerud, J. H. and Uman, G. (1993). Directions for AIDS education for Hispanic women based on analyses of survey findings. Public Health Reports, 108(3), 298-304.

Ford, K., Rubenstein, S., and Norris, A. (1994). Sexual behavior and condom use among urban, low-income, African-American and Hispanic youth. AIDS Education and Prevention, 6(3), 219-229.

Forrest, K. A., Austin, D. M., Valdes, M. I., Fuentes, E. G., and Wilson, S. R. (1993). Exploring norms and beliefs related to AIDS prevention among California Hispanic men. Family Planning Perspectives, 25(3), 111-117.
Gilmore, D. and Uhl, S. C. (1987). Further notes on Andalusian machismo. Journal of Psychoanalytical Anthropology, 10(4), 341-360.

Goldwert, M. (1985). Mexican machismo: The flight from femininity. Psychoanalytic Review, 72(1), 161-169.

Gollub, E. L. (1995). Women-centered prevention techniques and technologies. In A. O'Leary and L. S. Jemmott (Eds.), Women at Risk: Issues in the Primary Prevention of AIDS, 43-82. New York: Plenum Press.

Grimstead, O. A., Faigeles, B., Binson, D., and Eversley, R. (1993). Sexual risk for human immunodeficiency virus infection among women in high-risk cities. Family Planning Perspectives, 25(6), 252-256, 277.

Harrison, D. F., Wambach, K. G., Byers, J. B., Imershein, A. W., Levine, P., Maddox K., Quadagno, D. M., Fordyce, M. L., and Jones, M. A. (1990). AIDS knowledge and risk behaviors among culturally diverse women. AIDS Education and Prevention, 3(2), 79-89.

Hayes-Bautista, D. E., and Chapa, J. (1986). Latino terminology: Conceptual bases for standardized terminology. American Journal of Public Health, 77(1), 61-68.

Heise, L. L. and Elias, C. (1995). Transforming AIDS prevention to meet women's needs: A focus on developing countries. Social Science and Medicine, 40(7), 931-943.

Heise, L. L., Pitanguy, J., and Germain, A. (1994). Violence against women: The hidden health burden. Washington: The World Bank.

Hobfall, S. E., Jackson, A. P., Lavin, J., Britton, P. J., and Shepherd, J. B. (1994) Reducing inner-city women's AIDS risk activities: A study of single, pregnant women. Health Psychology, 13(5), 397-403.

Holmes, K. K., Karon, J. M., and Kreiss, J. (1990). The increasing frequency of heterosexually acquired AIDS in the United States, 1983-1988. American Journal of Public Health, 80(7), 858-862.

Hurtado, A. (1995). Variations, combinations, and evolutions: Latino families in the United States. In R. E. Zambrana (Ed.), Understanding Latino Families: Scholarship, Policy, and Practice, 40-61. Thousand Oaks, CA: Sage.

Ickovics, J. R. and Rodin, J. (1992). Women and AIDS in the United States: Epidemiology, natural history, and mediating mechanisms. Health Psychology, III (1), 2-16.

Izazola-Licea, J. A., Valdespino-Gomez, J. L., Gortmaker, S. L., Townsend, J., Becker, J., Palacios-Martinez, M., Mueller, N. E., and Sepulveda-Amor, J. (1991). HIV-1 seropositivity and behavioral and sociological risks among homosexual and bisexual men in six Mexican cities. Journal of Acquired Immune Deficiency Syndromes, 4, 614-622.

Kaemingk, K. L. and Bootzin, R. R. (1990). Behavior change strategies for increasing condom use. Evaluation and Program Planning, 13, 47-54.

Kalichman, S. C., Adair, V., Somlai, A. M., and Weir, S. S. (1995). The perceived social context of AIDS: Study of inner-city sexually transmitted disease clinic patients. AIDS Education and Prevention, 7(4), 298-307. 
Kalichman, S. C., Hunter, T. L., and Kelly, J. A. (1992). Perceptions of AIDS susceptibility among minority and nonminority women at risk for HIV infection. Journal of Consulting and Clinic Psychology, 60(5), 725-732.

Kelly, J. A., Murphy, D. A., Sikkema, K. J., and Kalichman, S. C. (1993). Psychological interventions to prevent HIV infection are urgently needed: New priorities for behavioral research in the second decade of AIDS. American Psychologist, 48(10), 1023-1034.

Kelly, J. A., Murphy, D. A., Washington, C. D., Wilson, T. S., Koob, J. J., Davis, D. R., Ledezma, G., and Devantes, B. (1994). The effects of HIV/AIDS intervention groups for high-risk women in urban clinics. American Journal of Public Health, 84(12), 1918-1922.

Kelly, J. A., St. Lawrence, J. S., Hood, H. V., and Brasfield, T. L. (1989). Behavioral intervention to reduce AIDS risk activities. Journal of Consulting and Clinic Psychology, 57(1), 60-67.

Kelly, J. A., St. Lawrence, J. S., Stevenson, L. Y., Hauth, A. C., Kalichman, S. C. Diaz, Y. E., Brasfield, T. L., Koob, J. J., and Morgan, M. G. (1992). Community HIV/AIDS risk reduction: The effects of endorsement by popular people in three cities. American Journal of Public Health, 82(11), 1483-1489.

Kenen, R. H. and Armstrong, K. (1992). The why, when, and whether of condom use among female and male drug users. Journal of Community Health, 17(5), 303-317.

Kline, A., Kline, E., and Oken, E. (1992). Minority women and sexual choice in the age of AIDS. Social Science and Medicine, 34(4), 447-457.

Launius, M. H. and Lindquist, C. U. (1988). Learned helplessness, external locus of control and passivity in battered women. Journal of Interpersonal Violence, 3(3), 307-318.

Lauver, D., Armstrong, K., Marks, S., and Schwarz, S. (1995). HIV risk status and preventive behaviors among 17,619 women. Journal of Obstetric, Gynecologic, and Neonatal Nursing, 24(1), 33-39.

Levine, O. H., Britton, P. J., James, T. C., Jackson, A. P., Hobfoll, S. E., and Lavin, J. P. (1993). The empowerment of women: A key to HIV prevention. Journal of Community Psychology, 21, 320-334.

LeVine, R. A. (1984). Properties of culture: An ethnographic view. In R. A. Shweder and R. A. LeVine (Eds.), Culture theory: Essays on Mind, Self, and Emotion, 67-87. New York: Cambridge University Press.

Ling, J. C., Franklin, B. A. K., Lindsteadt, J. F, and Gearon, S. A. N. (1992). Social marketing: Its place in public health. Annual Review of Public Health, 13, 341-362.

Liskin, L., Church, C. A., Piotrow, P. T., and Harris, J. A. (1989). AIDS Education-A beginning, Population Reports, Series L, No. 8. Baltimore: Johns Hopkins University, Population Information Program.

Liskin, L., Wharton, C., Blackburn, R., and Kestelman, P. (1990). Condomsnow more than ever, Population Reports, Series H, No. 8. Baltimore: Johns Hopkins University, Population Information Program.
Loizos, P. (1978). Violence and the family: Some Mediterranean examples. In M. P. Martin (Ed.), Violence and the Family, 183-195. Chichester, England: Wiley.

Magana, J. R. and Carrier, J. M. (1991). Mexican and Mexican-American male sexual behavior and spread of AIDS in California. Journal of Sex Research, 28(3), 425-441.

Magana, J. R. and Magana, H. A. (1992). Mexican-Latino children. In M. L. Stuber (Ed.), Children and AIDS, 33-43. Washington: American Psychiatric Press.

Marin, B. (1988). AIDS Prevention in non-Puerto Rican Hispanics. Rockville, MD: NIDA.

Marin, B. V., Gomez, C. A., and Hearst, N. (1993). Multiple heterosexual partners and condom use among Hispanics and non-Hispanic whites. Family Planning Perspectives, 25(4), 170-174.

Marin, B. V. and Marin, G. (1990). Effects of acculturation on knowledge of AIDS and HIV among Hispanics. Hispanic Journal of Behavioral Sciences, $12(2), 110-121$

Marin, B. V., Tschann, J. M., Gomez, C. A., and Kegeles, S. M. (1993). Acculturation and gender differences in sexual attitudes and behaviors: Hispanic vs. non-Hispanic white unmarried adults. American Journal of Public Health, 83(12), 1759-1761.

Marin, G. (1989). AIDS prevention among Hispanics: Needs, risk behaviors, and cultural values. Public Health Reports, 104(5), 411-415.

Marin, G. (1993). Defining culturally appropriate community interventions: Hispanics as a case study. Journal of Community Psychology, 21, 149-161.

Marin, G. and Marin, B. V. (1991). Research with Hispanic Populations. Newbury Park, CA: Sage.

Mason, H. R. C., Marks, G., Simoni, J. M., Ruiz, M. S., and Richardson, J. L. (1995). Culturally sanctioned secrets? Latino men's nondisclosure of HIV infection to family, friends, and lovers. Health Psychology, 14(1), 6-12.

Mays, V. M. and Cochran, S. D. (1988). Issues in the perception of AIDS risk and risk reduction activities by black and Hispanic/Latina women. American Psychologist, 43(11), 949-957.

Merson, M. (1993). Slowing the spread of HIV: Agenda for the 1990s. Science, $260,1266-1268$.

Mikawa, J. K., Morones, P. A., Gomez, A., Case, H. L., Olsen, D., and GonzalezHuss, M. J. (1992). Cultural practices of Hispanics: Implications for the prevention of AIDS. Hispanic Journal of Behavioral Sciences, 14(4), 421-433.

Mitchell, R. E. and Hodson, C. A. (1983). Coping with domestic violence: Social support and psychological health among battered women. Psychoanalytic Review, 7I(2), 305-317.

Moore, J. S., Harrison, J. S., and Doll, L. S. (1994). Interventions for sexually active, heterosexual women in the United States. In R. J. Clemente and J. L. Peterson (Eds.), Preventing Aids: Theories and Methods of Behavioral Interventions. New York: Plenum Press. 
Negy, C. and Woods, D.J. (1995). The importance of acculturation in understanding research with Hispanic Americans. Hispanic Journal of Behavioral Sciences, 14(2), 224-247.

Nyamathi, A., Bennett, C., Leake, B., Lewis, C., and Flaskerud, J. (1993). AIDSrelated knowledge, perceptions, and behaviors among impoverished minority women. American Journal of Public Health, 83(1), 65-71.

Nyamathi, A. M., Flaskerud, J., Bennett, C., Leake, B., and Lewis, C. (1994) Evaluation of two AIDS education programs for impoverished Latina women. AIDS Education and Prevention, 6(4), 296-309.

Nyamathi, A. M., Lewis, C., Leake, B., Flaskerud, J., and Bennett, C. (1995). Barriers to condom use and needle cleaning among impoverished minority female injection drug users and partners of injection drug users. Public Health Reports, 110(2), 167-172.

Nyamathi, A., Stein, J. A., and Brecht, M. (1995). Psychosocial predictors of AIDS-risk behavior and drug use behavior in homeless and drug addicted women of color. Health Psychology, 14(3), 265-273.

Nyamathi, A. and Vasquez, R. (1989). Impact of poverty, homelessness, and drugs on Hispanic women at risk for HIV infection. Hispanic Journal of Behavioral Sciences, 1I(4), 299-314.

O'Donnell, L., San Doval, A., Vornfett, R., and DeJong, W. (1994). Reducing AIDS and other STDs among inner-city Hispanics: The use of qualitative research in the development of video-based patient education. AIDS Education and Prevention, 6(2), 140-153.

O'Donnell, L., San Doval, A., Vornfett, R., and O'Donnell, C. R. (1994). STD prevention and the challenge of gender and cultural diversity: Knowledge, attitudes, and risk behaviors among black and Hispanic inner-city STD patients. Sexually Transmitted Diseases, 2I(3), 137-148.

O'Leary, A. and Jemmott, L.S. (1995). General issues in the prevention of AIDS in women. In A. O'Leary and L. S. Jemmott (Eds.), Women at Risk: Issues in the Primary Prevention of Aids, 1-12. New York: Plenum Press.

O'Leary, A., Jemmott, L. S., Suarez-Al-Adam, M., Fernandez, I., and AlRoy, C. (1993). Women and AIDS. In S. Matteo (Ed.), American Women in the 1990s. Today's Critical Issues, 173-192. Boston: Northeastern University Press.

Padilla, A. M. (1980). Acculturation as varieties of adaptation. In A. M. Padilla (Ed.), Acculturation: Theory, Models, and Some New Findings, 9-25. Boulder: Westview.

Panitz, D. R., McConchie, R. D., Saubev, S. R., and Fonseca, J. A. (1983). The role of machismo and the Hispanic family in the etiology and treatment of alcoholism in Hispanic American males. American Journal of Family Therapy, II(1), 31-44.

Parker, R. and Carballo, M. (1990). Qualitative research on homosexual and bisexual behavior relevant to HIV/AIDS. Journal of Sex Research, 27, 497-525.
Powell, D.R. (1995). Including Latino fathers in parent education and support programs. In R. E. Zambrana (Ed.), Understanding Latino Families: Scholarship, Policy, and Practice, 85-106. Thousand Oaks, CA: Sage.

Quinn, T. C. and Cates, W. (1992). Epidemiology of sexually transmitted diseases in the 1990s. In T. C. Quinn (Ed.), Sexually Transmitted Diseases, 1-37. New York: Raven.

Ramirez, J., Suarez, E., Rosa, G., Castro, M. A., and Zimmerman, M. A. (1994). AIDS knowledge and sexual behavior among Mexican gay and bisexual men. AIDS Education and Prevention, 6(2), 163-174.

Rapkin, A. J. and Erickson, P. I. (1990). Differences in knowledge of and risk factors for AIDS between Hispanic and non-Hispanic women attending an urban family planning clinic. AIDS, 4(9), 889-899.

Reiss, I. L. and Leik, R. K. (1989). Evaluating strategies to avoid AIDS: Number of partners vs. use of condoms. Journal of Sex Research, 26(4), 411-433.

Remez, L. (1993). Consistent condom use is rare among never-married American women, 1988 survey shows. Family Planning Perspectives, 25(6), 283-284.

Robey, B., Rutstein, S. O., Morris, L., and Blackburn, R. (1992). The Reproductive Revolution: New Survey Findings, Population Reports, Series M, No. 11 . Baltimore: Johns Hopkins University, Population Information Program.

Sabogal, F., Perez-Stable, E. J., Otero-Sabogal, R., and Hiatt, R. A. (1995). Gender, ethnic, and acculturation differences in sexual behavior: Hispanic and non-Hispanic white adults. Hispanic Journal of Behavioral Sciences, 17(2), 139-159.

San Doval, A., Duran, R., O’Donnell, L., and O'Donnell, C. (1995). Barriers to condom use in primary and nonprimary relationships among Hispanic STD clinic patients. Hispanic Journal of Behavioral Sciences, 17(3), 385-397.

Schilling, R. F., El-Bassel, N., Schinke, S. P., Gordon, K., and Nichols, S. (1991). Building skills of recovering women drug users to reduce heterosexual AIDS transmission. Public Health Reports, 106(3), 297-304.

Sikkema, K. J., Heckman, T. G., Kelly, J. A., Anderson, E. S., Winett, R. A. Solomon, L. J., Wagstaff, D. A., Roffman, R. A., Perry, M. J., Cargill, V., Crumble, D. A., Fuqua, R. W., Norman, A. D., and Mercer, M. B. (1996). Prevalence and Predictors of HIV Risk Behaviors Among Women Living in Low-Income, Inner-City Housing Developments. American Journal of Public Health, 86(8), 1123-1128.

Silvestre, A. J., Kingsley, L. A., Wehman, P., Dappen, R., Ho, M., and Rinaldo, C. R. (1993). Changes in HIV rates and sexual behavior among homosexual men, 1984 to 1988/92. American Journal of Public Health, 83, 578-580.

Singer, M., Flores, C., Davison, L., Burke, G., Castillo, Z., Scanlon, K., and Rivera, M. (1990). SIDA: The economic, social, and cultural context of AIDS among Latinos. Medical Anthropology Ouarterly, 4(1), 72-114.

Solomon, M. Z. and DeJong, W. (1989). Preventing AIDS and other STDs through condom promotion: A patient education intervention. American Journal of Public Health, 79(4), 453-458. 
Stall, R., Coates, T. J., and Hoff, C. (1988). Behavioral risk reduction for HIV infection among gay and bisexual men: A review of results from the United States. American Psychologist, 43, 878-885.

Stein, Z. (1990). HIV prevention: The need for methods women can use. American Journal of Public Health, 80, 460-462.

Stewart, M. (1993). Minorities, women who lack influence on partner often fail to use condoms. Family Planning Perspectives, 25(3), 143-144.

Straus, M. (1983). Societal morphogenesis and intrafamily violence in cross-cultural perspective. In R. J. Gelles and C. P. Cornell (Eds.), International Perspectives on Family Violence, (pp. 27-43). Lexington, MA: Lexington.

Straus, M. A. and Smith, C. (1990). Physical violence in American families. New Brunswick, NJ: Transaction.

Suarez, M. (1995). The Impact of Psychological and Physical Abuse and Hypermasculinity on the Ability of Hispanic Women to Negotiate Safer Sex. Unpublished Master's Thesis, Rutgers University, New Brunswick, NJ.

Suarez, M., Raffaelli, M., and O'Leary, A. (1995). Physical and Psychological Abuse in an Inner-City Hispanic Population. Paper presented at the Society of Behavioral Medicine, San Diego, CA.

Thompson, W. N. (1991). Machismo: Manifestations of a cultural value in the Latin-American casino. Journal of Gambling Studies, 7(2), 143-164.

Torres, S. (1991). A comparison of wife abuse between two cultures: Perceptions, attitudes, nature, and extent. Issues in Mental Health Nursing, 12(1), 113-131.

U.S. Bureau of the Census. (1995). Residence Population Estimate for 1995. Washington: U.S. Bureau of the Census.

Vega, W. and Miranda, M. R. (1985). Stress and Hispanic mental health: Relating Research to Service Delivery. Rockville, MD: U.S. Department of Health and Human Services, National Institute of Mental Health, Public Health Service.

Wagstaff, D. A., Kelly, J. A., Perry, M. J., Sikkema, K. J., Solomon, L. J., Heckman, T. G., Anderson, E. S., Roffman, R. A., Cargill, V., Norman et al (1995). Multiple partners, risky partners, and HIV risk among low-income urban women. Family Planning Perspectives, 27(6), 241-245.

Weeks, M. R., Schensul, J. J., Williams, S. S., Singer, M., and Grier, M. (1995). AIDS prevention for African-American and Latina women: Building culturally and gender-appropriate intervention. AIDS Education and Prevention, $7(3), 251-263$.

Weiss, E. and Gupta, G. R. (1993). Women facing the challenge of AIDS. In G. Young, V. Samarasinghe, and K. Kusterer (Eds.), Women at the Center: Development Issues and Practices for the 1990s, 168-181. West Hartford: Kumarian Press.

Wiest, R. E. (1983). Male migration machismo and conjugal roles: Implications for fertility control in a Mexican municipio. Journal of Comparative Family Studies, 14(2), 167-181.

World Health Organization. (1992). The global AIDS strategy (WHO AIDS Series 11). Geneva: World Health Organization.
Winkelstein, W., Samuel, M., Padian, N. S., Wiley, J. A., Lang, W., Anderson, R. E., and Levy, J. A. (1987). The San Francisco Men's Health Study: III. Reduction in Human Immunodeficiency Virus transmission among homosexual/bisexual men, 1982-1986. American Journal of Public Health, 76, 685-689.

Worth, D. (1989). Sexual decision making and AIDS: Why condom promotion among vulnerable women is likely to fail. Studies in Family Planning, 20(6), 297-307.

Wurzman, I. (1982-1983). Cultural values of Puerto Rican opiate addicts: An exploratory study. American Journal of Drug and Alcohol Abuse, 9(2), 141-153.

Wyatt, G. E. (1994). The sociocultural relevance of sex research: Challenges for the 1990s and beyond. American Psychologist, 49(8), 748-754. 